\title{
Determination of the working area of a hydraulic excavator
}

\author{
Victor Shestakov ${ }^{1}$, Pavel Bezkorovainyy ${ }^{2}$, and Tatyana Franz ${ }^{1}$ \\ ${ }^{1}$ Ural State Mining University, 620144, Kuibyshev st., 30, Ekaterinburg, Russia \\ ${ }^{2}$ Karaganda State Technical University, 100027, Nursultan Nazarbayev Ave., 56, Karaganda, Repub- \\ lic of Kazakhstan
}

\begin{abstract}
The relevance of the work is due to the need of the design departments involved in the design of hydraulic excavators in techniques that reduce the mass of excavators while providing the required technological capabilities. Existing methods are aimed at determining the size of working equipment on the condition of providing a given working area. The methods are based on an algorithm for calculating the boundaries of the working area for the input dimensions of the boom, stick and bucket, if the obtained boundaries do not correspond to the specified ones, then the dimensions of the equipment are adjusted and the calculations are repeated. The boundaries of the working zone determined by these algorithms do not take into account the power capabilities - the bucket can be at a given point, but the realized forces on the teeth do not ensure separation of the rock. The article discusses the methodology in which possible digging efforts are calculated at all points where the bucket can be located.

Results. For a hydraulic excavator with working equipment "direct shovel", a mathematical model for calculating digging forces, an algorithm and a program in algorithmic language have been developed to determine possible forces in the elements of the working equipment.
\end{abstract}

\section{Introduction}

The effectiveness of their operation has been the subject of a large number of studies [1,2]. When designing hydraulic excavators, technological parameters such as digging in a given work area are set. In existing methods, the working area is determined by the geometric dimensions of the working equipment (boom, stick, bucket) [3-5], but at the same time, the required digging forces will not be provided at some points in the working area, and the stability of the excavator is also not checked. On excavators, control systems are introduced to ensure digging along predetermined paths. The systems include a processor that calculates the control signals of the mechanisms of the equalizer according to the models compiled according to geometric dependences [6-14], but the trajectories being implemented are often different from the set ones, since the influence of efforts is not taken into account in any way. Thus, research is required to refine the models. 


\section{Research method}

To calculate the possible digging efforts within the area determined by the geometric dimensions, we developed a mathematical model. The initial data for it are the geometric and power parameters of the working equipment and the ex-cavator as a whole. The scheme for compiling the expression is shown in Fig. 1.

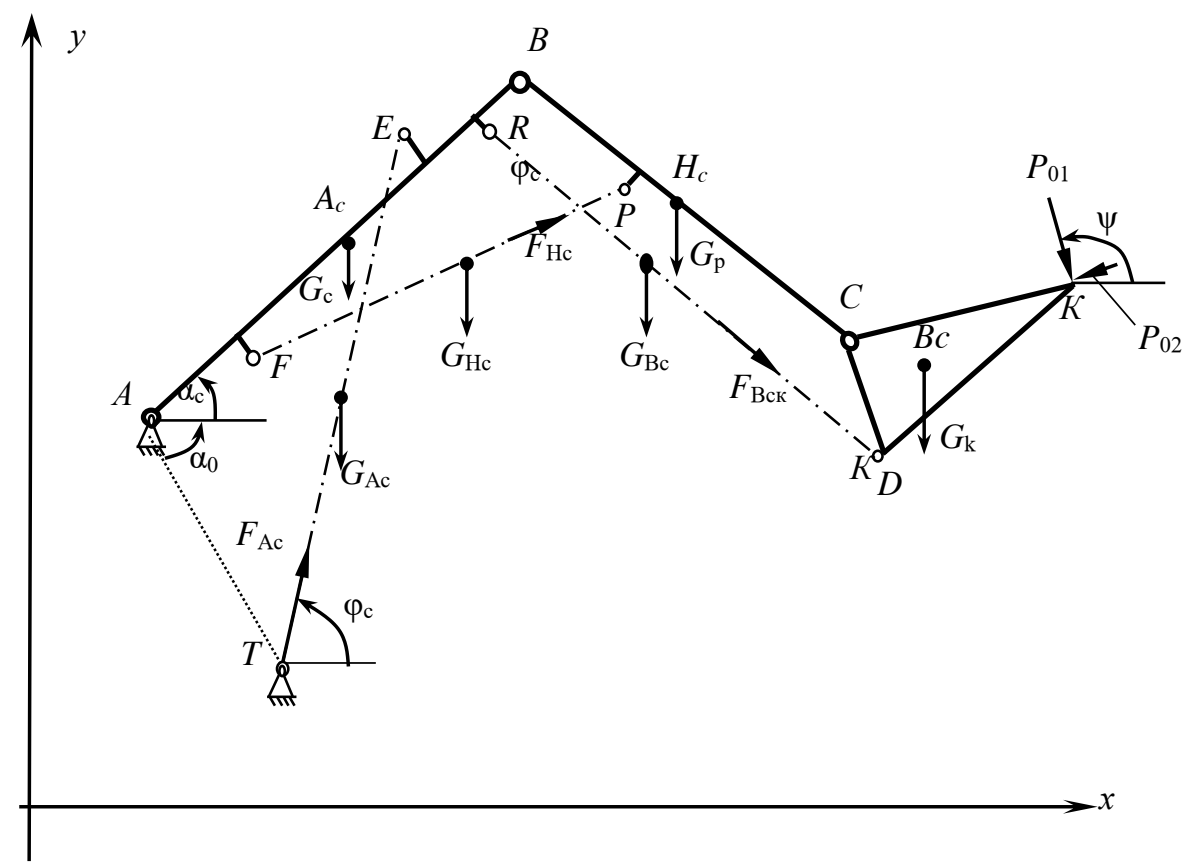

Fig. 1. Scheme of working equipment:

A, T, E, F, P, R, B, C, D - hinges; K is the top of the bucket tooth; KSD - a profile profile of the bucket; $\mathrm{CB}$ - handle; $\mathrm{AB}$ - arrow; TE, FP, RD - hydraulic cylinders for turning the boom, arm, and bucket; $\mathrm{G}_{\mathrm{c}}, \mathrm{G}_{\mathrm{p}}, \mathrm{G}_{\mathrm{k}}, \mathrm{G}_{\mathrm{Ac}}, \mathrm{G}_{\mathrm{Hc}}, \mathrm{G}_{\mathrm{Bc}}$ - gravity of the boom, stick, bucket, boom hydraulic cylinders, stick, boom bucket, stick, bucket; $\mathrm{A}_{\mathfrak{c}}, \mathrm{H}_{\mathrm{c}}, \mathrm{B}_{\mathrm{c}}$ - coordinates of the center of gravity of the boom, stick and bucket; $\alpha_{c}, \alpha 0, \varphi_{c}, \psi$ - angles

The model includes expressions for calculating the coordinates of the points and the angles of inclination of the elements of the working equipment according to their linear dimensions (in the formulas the dimensions are indicated by the points of the diagram, and the angles by the angle sign and three points), the coordinates of the boom attachment to the platform and the dimensions of the hydraulic cylinders LAc.

The angle of the line $\mathrm{AB}$ to the horizon

$$
\alpha_{c}=\operatorname{arcos} \frac{A E^{2}+A T^{2}-L_{\mathrm{Ac}}^{2}}{2 \cdot A E \cdot A T}-\angle_{B A E}-\alpha_{0} .
$$

Arrow-stick joint axis coordinates (point B)

$$
x_{B}=x_{A}+A B \cdot \cos \alpha_{c} ; y_{B}=y_{A}+A B \cdot \sin \alpha_{c} .
$$

The calculation of the coordinates of the handle are determined relative to point $\mathrm{B}$ by the angle determined by the length of the hydraulic cylinder of the handle $L_{\mathrm{Hc}}$ (section $F P$ on figure 1): 


$$
\begin{aligned}
& \beta=\pi+\alpha_{c}-r \cos \frac{B F^{2}+B P^{2}-L_{H c}^{2}}{2 \cdot B F \cdot B P}-\angle_{B F F^{\prime}}-\angle_{P B P} . \\
& x_{C}=x_{B}+B C \cdot \cos \beta ; y_{C}=y_{B}+B C \cdot \sin \beta .
\end{aligned}
$$

The coordinates of the top of the bucket tooth along the length of the bucket hydraulic cylinder (LBc):

$$
\begin{aligned}
& \gamma=\beta-\pi-\angle_{R C R^{\prime}}+\angle_{D C R} ; \quad \angle_{D C R}=\operatorname{arcos} \frac{C D^{2}+C R^{2}-L_{B c}{ }^{2}}{2 \cdot C D \cdot C R} ; \\
& x_{K}=x_{C}+C K \cdot \cos \left(\gamma+\angle_{D C K}\right) ; y_{K}=y_{C}+C K \cdot \sin \left(\gamma+\angle_{D C K}\right) .
\end{aligned}
$$

When calculating the possible digging forces on the bucket teeth, the gravity of the elements is taken into account.

To calculate the forces on the hydraulic cylinder rods, the equilibrium conditions are used with respect to the hinges $\mathrm{C}, \mathrm{B}$ and $\mathrm{A}$.

$$
\begin{gathered}
F_{\mathrm{Ac}}=\frac{G_{\mathrm{c}}\left(x_{\mathrm{Ag}}-x_{A}\right)+G_{\mathrm{p}}\left(x_{\mathrm{Hg}}-x_{A}\right)+G_{\mathrm{K}}\left(x_{B g}-x_{A}\right)+G_{\mathrm{Ac}}\left(\frac{x_{\mathrm{T}}+x_{\mathrm{E}}}{2}-x_{A}\right)+G_{\mathrm{Hc}}\left(\frac{x_{\mathrm{F}}+x_{\mathrm{P}}}{2}-x_{A}\right)+}{\frac{+G_{\mathrm{Bc}}\left(\frac{x_{\mathrm{R}}+x_{\mathrm{D}}}{2}-x_{A}\right)+P_{\mathrm{y}}\left(x_{\mathrm{\kappa}}-x_{A}\right)+P_{\mathrm{x}}\left(y_{\mathrm{K}}-y_{A}\right)}{L_{A T} \sin \left(\pi-\alpha_{0}-\varphi_{c}\right)}} \\
F_{\mathrm{Hc}}=\frac{G_{\mathrm{p}}\left(x_{\mathrm{Hg}}-x_{B}\right)+G_{\mathrm{K}}\left(x_{\mathrm{Bg}}-x_{B}\right)+G_{\mathrm{Bc}}\left(\frac{x_{\mathrm{R}}+x_{\mathrm{D}}}{2}-x_{B}\right)+}{\frac{+P_{\mathrm{y}}\left(x_{\mathrm{K}}-x_{B}\right)+P_{\mathrm{x}}\left(y_{\mathrm{K}}-y_{B}\right)+0,5 G_{\mathrm{Hc}}\left(x_{P}-x_{B}\right)}{L_{B P} \sin \angle F P B}} \\
F_{\mathrm{Bc}}=\frac{G_{\mathrm{K}}\left(x_{\mathrm{Bg}}-x_{C}\right)+P_{\mathrm{y}}\left(x_{\mathrm{K}}-x_{C}\right)+P_{\mathrm{x}}\left(y_{\mathrm{K}}-y_{C}\right)-0,5 G_{\mathrm{Bc}}\left(x_{D}-x_{C}\right)}{L_{C D} \sin \angle R D C}
\end{gathered}
$$

where FAc, FHc, FBc - efforts on the rods of the boom, stick and bucket hydraulic cylinders;

$P_{x}=-P_{01} \cos \psi-P_{02} \sin \psi, P_{y}=-P_{01} \sin \psi+P_{02} \cos \psi$ - projection of the resistance to digging.

The simplest form of expression is in the transition from efforts on the teeth to efforts in specific elements. When calculating the parameters of both hydraulic and mining rope excavators, the force on the teeth of the bucket when separating the soil from the massif is determined by the formula N.G. Dombrowski - V.P. Goryachkina [4]:]:

$$
P_{01}=k_{1} B_{\mathrm{K}} \mathrm{c},
$$

where k1 - - specific soil resistance to digging; Вк - bucket width; $\mathrm{c}$ is the thickness of the soil chips in a direction perpendicular to the path of movement of the cutting tool. 
Chip thickness is determined by the bucket filling condition. In hydraulic excavators with working equipment, a direct shovel digging most often occurs by turning the bucket and less often when turning the handle and boom.

In the process of digging by turning the bucket, the efforts on the teeth depend both on the forces developed by the bucket hydraulic cylinders and on the sizes and tilt angles of the elements transmitting the forces to the bucket. In the case of digging by turning the bucket during the calculation of the forces, it is usually considered that the handle and the boom are stationary, and are held by the corresponding hydraulic cylinders. The boom and stick immobility is ensured if the maximum reactive force on the hydraulic cylinder rods, which is determined by the working area and the setting pressure of the safety valves, exceeds the reaction value from the force on the bucket teeth [10].

If the reactive force is lower than the required, then there will be a "subsidence" of the rods of the boom or stick hydraulic cylinders and the force on the bucket teeth will decrease. In the model of calculating the efforts of digging, this feature should be taken into account.

To calculate the possible efforts on the bucket teeth according to the expressions obtained in the algorithm, the force is initially set that is obviously greater than the possible for the excavator under consideration. This force determines the force on the rods of the hydraulic cylinders of the bucket, stick and boom, and also checks for stability. If at least one of the forces on the rods is greater than the working force of the corresponding hydraulic cylinder, or the stability of the excavator is impaired, then the force on the teeth of the bucket decreases and the calculation is repeated. Such a consistent decrease in effort on the teeth determines the possible digging force at each point of the working area.

\section{Results}

The compiled mathematical model, using the algorithm, is converted into a simulation model of the workflow. The model includes four cycles. In the outer loop, a stability check is performed. If the stability condition is not met, then the force on the teeth of the bucket is reduced and the calculations are repeated until stability is ensured. In the third cycle, a discrete extension of the boom hydraulic cylinder rods (from the minimum to the maximum value) is ensured, which ensures the rotation of the boom relative to the heel and the movement of the "boom-stick" axis. In the second cycle, for each position of the boom, a discrete extension of the rods of the handle hydraulic cylinders is implemented, which ensures the rotation of the handle and the movement of the bucket to the digging point. In the internal cycle, for each position of the handle, a discrete extension of the rods of the bucket hydraulic cylinders is realized and, due to this, digging by turning the bucket. The algorithm provides for work when digging by turning the handle, in that mode the internal cycle is excluded and digging occurs without turning the bucket relative to the handle.

The program provides for the conclusion of the results in tabular form and in the form of a figure (see Fig. 2).).

\section{Findings}

The developed mathematical model, algorithm and program in the algorithmic language allow:

- determine the forces within the working area with the given parameters of the working equipment and hydraulic drive mechanisms;

- determine the efforts of digging, taking into account the stability of the excavator; 
- determine the parameters of the hydraulic system according to the condition of ensuring the required digging efforts.

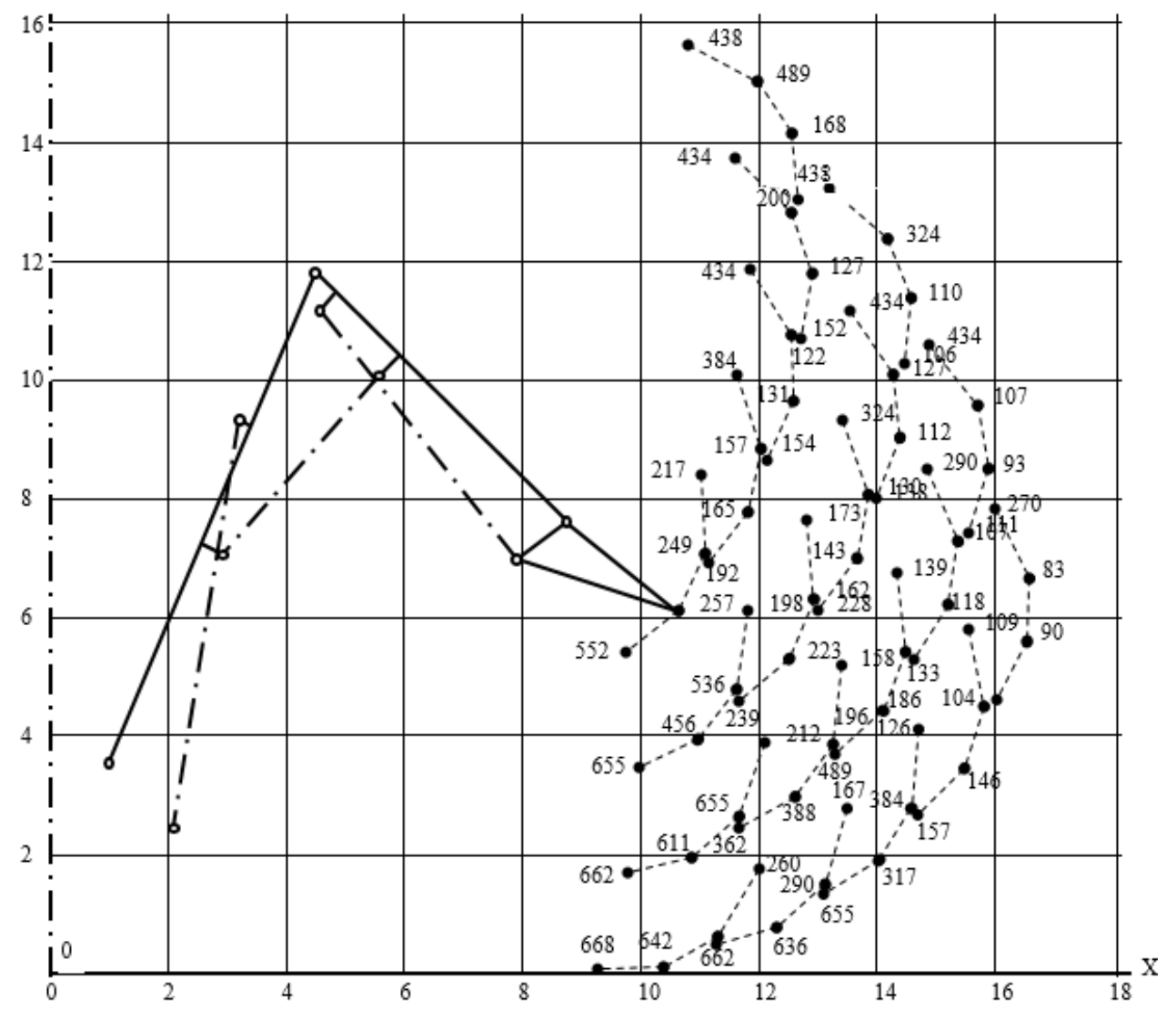

Fig. 2. The results of the calculation of efforts

\section{References}

1. A.P. Komissarov, Yu.A. Lagunova, V.S. Shestakov, Design of mining excavators, 228 (M.: Innovative engineering, 2017)

2. O.A. Lukashuk, A.P. Komissarov, K.Y. Letnev, IOP Conference Series: Materials Science and Engineering, 709 (2), 022083 (2020)

3. P.A. Pobegaylo, Powerful single-bucket hydraulic excavators: Selection of the basic geometric parameters of the working equipment in the early stages of design, 296 (M.: LENAND, 2014)

4. D.P. Volkov, V.Ya. Krikun, P.Ya. Totolin et al., Machines for earthworks: Textbook. for universities, 448 (1992)

5. P.A. Pobegailo, Mining Information and Analytical Bulletin, 5, 107 - 114 (2016)

6. Q.H. Le, Y. Soon-Yong, Proc. on 11th International Conference on Control, Automation and Systems, Gyeonggi-do, Korea (South), 26-29 Oct., 941-945 (2011)

7. A.J. Koivo, M. Thoma, E. Kocaoglan, J. Andrade-Cetto, Journal of Aerospace Engineering, 9, 10-18 (1996)

8. D.A. Bradley, D.W. Seward, J.E. Mann, M.R. Goodwin, Automation in Construction, 2(3), 217 - 228 (1993) 
9. P.A. Pobegailo, Mining Information and Analytical Bulletin, 5, 212 - 225 (2015). A.P. Komissarov, V.S. Shestakov, Mining equipment and electromechanics, 8, 20-24 (2013)

10. Y.A. Lagunova, A.P. Komissarov, O.A. Lukashuk, IOP Conference Series: Materials Science and Engineering, 327 (5), article no 052024 (2018)

11. D. Seward, D. Bradley, J. Mann, M. Goodwin, Proc. ninth International Symposium on Automation and Construction, Tokyo, 743-750 (1992)

12. S. Frimpong, Y. Hu, H. Inyang, International Journal of Geomechanics, 8(1), 20-29 (2009)

13. F. Geu Flores, A. Kecskemethy, A. Pottker, Workspace analysis and maximal force calculation of a face-shovel excavator using kinematical transformers. 12th IFToMM World Congress, Besancon, June 18-21, 6 (2007) 